\title{
MENINGITIS CAUSED BY CRYPTOCOCCUS INFECTION IN A NON-HIV PATIENT: A CASE REPORT
}

\author{
Rakesh Kumar¹, Faiyaz Alam², Dhananjay Kumar3, Aninda Sen ${ }^{4}$
}

\section{HOW TO CITE THIS ARTICLE:}

Rakesh Kumar, Faiyaz Alam, Dhananjay Kumar, Aninda Sen. "Meningitis Caused by Cryptococcus Infection in a Non-HIV Patient: A Case Report". Journal of Evolution of Medical and Dental Sciences 2014; Vol. 3, Issue 47, September 25; Page: 11446-11449, DOI: 10.14260/jemds/2014/3496

ABSTRACT: The incidence of cryptococcal meningitis has increased in recent years, both in human immunodeficiency virus (HIV) positive and non-HIV patients. Chronic high dose steroid may precipitate such an immunocompromised state and thus create susceptibility to fungal infection. We report a fatal case of cryptococcal meningitis in non-HIV male caused by Cryptococcus neoformans.

KEYWORDS: Cryptococcal infection, chronic steroid use, non-HIV patient.

INTRODUCTION: Cryptococcosis occurs worldwide and mostly affects immunodeficient individuals. Rarely, even normal hosts can also become so diseased. ${ }^{1}$

The incidence of cryptococcal meningitis has increased in recent years, both in human immunodeficiency virus (HIV) positive and in HIV-negative patients. Among all fungi causing meningitis, Cryptococcus neoformans remains the most common. ${ }^{2}$

The two encapsulated yeast species Cryptococcus neoformans Serotype A (i.e., C. neoformans var. grubii) \& Serotype D (i.e., C. neoformans var. neoformans) and C. gattii (serotypes B and C), are the causative agents of Cryptococcosis, and can cause life-threatening infections of the central nervous system, such as meningoencephlitis. ${ }^{3}$

Chronic steroid use can predispose patients to many infections. High steroid use can decrease migration and inhibit chemotaxis of neutrophils, inhibit phagocytosis and intracellular killing and decrease production of proinflammatory cytokine.

CASE REPORT: A 56 year old male resident of a suburban area in Bihar, India, who was farmer by occupations was admitted with high grade fever, severe headache and repeated episodes of vomiting for 10 days, and altered sensorium for last 4 days. The patient was diabetic and a known case of chronic obstructive pulmonary disease (COPD) for many years and he was under self-medication of high dose chronic steroid for last 7 years.

He had no history of seizures, ear discharge or earache, nor any focal neurological deficit, head trauma, blood transfusion, or high risk behaviour. There was no history of tuberculosis, malignancy or any other such chronic illness except diabetes, and was under irregular treatment for the same and self-medication of high dose steroid for last 7 years for COPD. He also reported contact with a large pigeon population in the area of his residence.

On general examination, patient was slightly confused, exhibited cushingoid facies with central obesity. Oral temperature was $38.4^{\circ} \mathrm{C}$, heart rate $90 / \mathrm{min}$, blood pressure $126 / 78 \mathrm{~mm} \mathrm{Hg}$, respiratory rate $24 / \mathrm{min}$, and oxygen saturation was $96 \%$ on room air.

Neurological examination showed that the patient was slightly confused and during the mini mental state examination he scored 18 points. Neck rigidity and Kernig's sign were positive. 
Planters were bilaterally extensor, and deep tendon reflexes were diminished. Examination of other systems revealed no obvious abnormality.

Initial laboratory results included a normal white blood cell count of $8200 / \mathrm{cu}$. mm with $72 \%$ neutrophils, 22\% lymphocyte, 5\% eosinophil and 1\% monocyte. A hemoglobin count of $10 \mathrm{mg} / \mathrm{dl}$ and platelet count of $98000 / \mathrm{cu}$. mm was recorded. Serum electrolyte levels were within normal limits. Liver function test and renal function test were within normal limits. Patient was tested for HIV antibodies but found non-reactive. A computerized tomography (CT) scan of head and chest X-ray were both normal.

Cerebrospinal fluid (CSF) examination revealed 104 white blood cells predominantly lymphocytes, with protein of $52.4 \mathrm{mg} / \mathrm{dl}$ and glucose of $36 \mathrm{mg} / \mathrm{dl}$. Corresponding blood sugar was 212 $\mathrm{mg} / \mathrm{dl}$. No microorganisms were seen after Gram stain and Ziehl-Neelsen (Z-N) stain. India ink preparation showed cryptococci with capsules (Figure 1 and Figure 2).

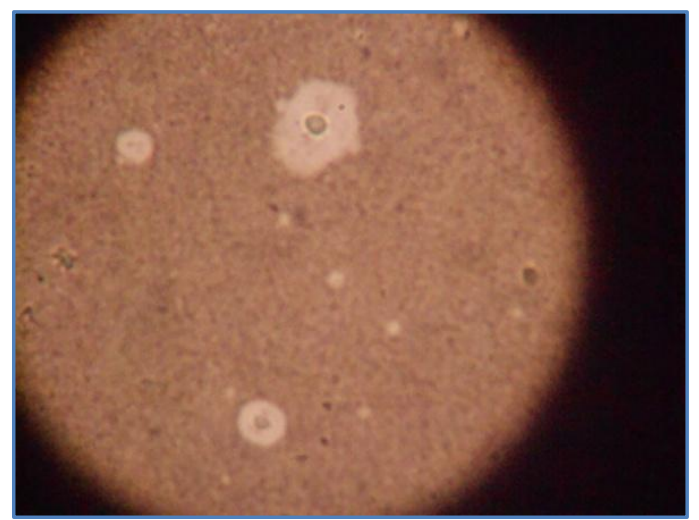

Fig. 1: Encapsulated Cryptococci

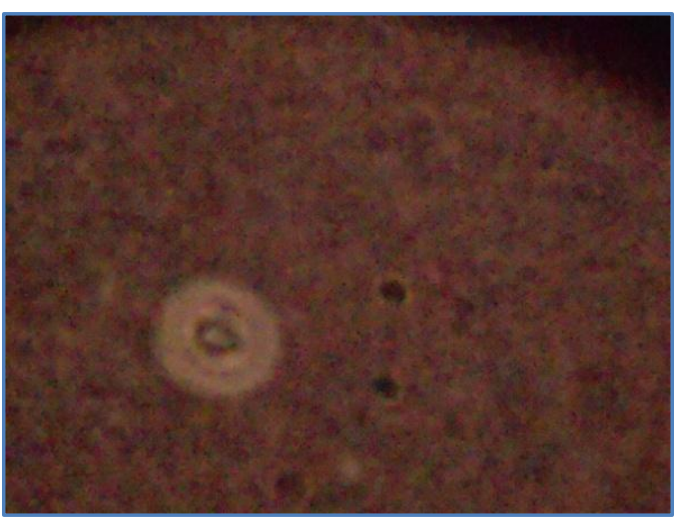

Fig. 2: Encapsulated cryptococcus

A culture was performed on Sabouraud's Dextrose Agar (SDA), which yielded mucoid colony. Urease test was performed and found positive. The isolate was sub-cultured on canavanine glycine bromothymol blue (CGB) to differentiate C. neoformans from C. gattii. The CGB media shows no change of color. Thus the isolate was characterized as $C$. neoformans. The CSF cryptococcal latex agglutination test was positive.

Treatment was started with Amphotericin B at $1 \mathrm{mg} / \mathrm{kg} /$ day with intravenous fluids and mannitol. Renal function and serum electrolyte were regularly monitored. The patient had to be discharged against medical advice and was reported to have died at home two days later.

DISCUSSION: Cryptococcus neoformans is found in commonly at sites contaminated with pigeon excreta. Cryptococcal meningitis is a common opportunistic infection in Acquired Immunodeficiency Syndrome (AIDS). However, its prevalence among immunocompetent host is not well established, but may be increasing. ${ }^{4-9}$ Potential explanation for the increase include the success of the antiretroviral therapy and a difference in virulence among varieties of Cryptococcus neoformans serotypes namely var. neoformans, var. grubii and var. gattii. ${ }^{9}$

Cryptococcal meningitis has also been sporadically reported in HIV-negative patients caused by organ transplant and chemotherapy related immunosuppression, reticuloendothelial 
malignancies, corticosteroid therapy and sarcoidosis.10-11 Occasionally, no obvious underlying cause can be detected.12,13 Despite all the measures taken, our patient could not survive and died of late presentation. Despite the availability of newer antifungal agents such as fluconazole, cryptococcal disease in HIV-negative hosts continues to be associated with substantial morbidity and mortality. ${ }^{14}$

Mortality rates can vary from 0 to $47 \%$ in non-HIV- infected patients. Moreover, in tropical countries it can vary from 0 to $38 \%$ where a low percentage of patients have underlying diseases. ${ }^{15}$

Our patient was diabetic and suffered from chronic obstructive pulmonary disease with chronic high dose steroid use. While Amphotericin B (0.7-1 mg/kg per day) alone for six to ten weeks or in combination with fluncytosine $\left(100 \mathrm{mg} / \mathrm{kg}\right.$ per day in four divided doses) for two weeks ${ }^{16}$ can be administered in such cases, our patient was treated with Amphotericin B alone. Death was due to late presentation. Early diagnosis, for cryptococcal meningitis early in the course of disease might have saved our patient.

Thus it can be concluded that clinician should keep in mind the possibility of cryptococcal infection even in immunocompetent patients. Late diagnosis may lead to a poor outcome.

\section{REFERENCES:}

1. Seaton A, Seation D, Leitch AG. Crofton and Douglas's Respiratory Diseases, $14^{\text {th }}$ ed Oxford University Press, Delhi. 1989; 455.

2. Satpute MG, Telang NV, Litake GM, Niphadkar KB, Joshi SG. Prevalence of Cryptococcal Meningitis at a Tertiary care centre in Western India (1996-2005). J Med Microbiol. 2006; 55: 1301-1302.

3. Voelz K, Lammas Da, May RC. Cytokine Signalling Regulates the Outcome of Intracellular Macrophage Parasitism by Cryptococcus neoformans. Infect Immun. 2009; 77: 3450-3457.

4. Klein NC, Go CHU, Cunha BA. Infections associated with steroid use. Infect Dis Clin North Am. 2001; 15 (2) 423-32.

5. Bicanic T. Cryptococcal meningitis. Br Med Bull. 2005; 72, 99-118.

6. Ecevit IZ. The poor Prognosis of central nervous system Cryptococcal among non immunosuppresed patients: a call for better disease recognition and evaluation of adjuncts to antifungal therapy. Clin Infect Dis. 2006; 42: 1443-7.

7. Imwidthaya P. Cryptococcosis in AIDS. Postgrad Med J. 2000; 76(892):85-8

8. Lui G, Lee N. Cryptococcosis in apparently immunocompetent patients. QJ Med. 2006; 99 (3): 143.

9. Drower F. The French Cryptococcosis Study Group: Determinants of disease presentation and outcome during Cryptococcosis: the crypto A/D study. PLos Med. 2007; 4 (2) :e21

10. Pandit L, Agarwal A, Shenoy S, Kamath G. Cryptococcal Meningitis and pulmonary crptococosis in a non-HIV Infected. Patient.Eur J Gen Med. 2006; 3:80-82.

11. Viviani MA, Tortorano AM, Ajullo L. Cryptococcus. In: Clinical mycology, $1^{\text {st }}$ ed. Anaissie EJ, McGinnis MR, Pfaller. MA Elsevier Science USA. 2003; 240-559.

12. Madan M, Ranjitham M, Chandrasekharan S, Sudhakar. Cyptococcal meningitis in immunocompetent individuals. J Assoc Physicians India. 1999; 47:933-934.

13. Prasad KN, Agarwal J, Nag V, Verma AK, Dixit AK, Ayyagari A. Cryptococcal infection in patients with clinically diagnosed meningitis in a tertiary care center. Neurol India. 2003; 51:364-366. 
14. Pappas PG, Prefect JR, Cloud GA, Larsen RA, Pankey GA, Lancaster DJ, Henderson H, Kauffman CA, Haas DW, Saccente M, Hamill RJ, Hollway MS, Warren RM, Dismukes WE. Cryptococcosis in human immunodeficiency virus-negative patients in the era of effective azole therapy. Clin Infect Dis. 2001; 33:690-699.

15. Shih CC, Chen YC, Chang SC, Luh KT, Hsich WC. Cryptococcal meningitis in non-HIV- infected patients. QJ Med. 2000; 93:245-251.

16. King JW, De Witt, ML. Cryptococcosis. Available: http://emedicine.medscape.com/article/215354-overview. Accessed 12 July 2010.

\section{AUTHORS:}

1. Rakesh Kumar

2. Faiyaz Alam

3. Dhananjay Kumar

4. Aninda Sen

\section{PARTICULARS OF CONTRIBUTORS:}

1. Assistant Professor, Department of Medicine, Katihar Medical College, Katihar, Bihar, India.

2. Assistant Professor, Department of Medicine, Katihar Medical College, Katihar, Bihar, India.

3. Assistant Professor, Department of Microbiology, Katihar Medical College, Katihar, Bihar, India.
4. Professor, Department of Microbiology, Katihar Medical College, Katihar, Bihar, India.

\section{NAME ADDRESS EMAIL ID OF THE CORRESPONDING AUTHOR:}

Aninda Sen,

Department of Microbiology, Katihar Medical College,

Katihar-854105, Bihar, India.

Email: aninda_0428@yahoo.com

Date of Submission: 09/09/2014.

Date of Peer Review: 10/09/2014.

Date of Acceptance: 17/09/2014.

Date of Publishing: 25/09/2014. 